\title{
Carrier Formation Dynamics of Organic Photovoltaics as Investigated by Time-Resolved Spectroscopy
}

\author{
Kouhei Yonezawa, ${ }^{1}$ Minato Ito, ${ }^{1}$ Hayato Kamioka, ${ }^{1,2}$ Takeshi Yasuda, ${ }^{3}$ \\ Liyuan Han, ${ }^{3}$ and Yutaka Moritomo ${ }^{1,2}$ \\ ${ }^{1}$ Graduate School of Pure and Applied Science, University of Tsukuba, Tsukuba 305-8571, Japan \\ ${ }^{2}$ Tsukuba Research Center for Interdisciplinary Materials Science (TIMS), University of Tsukuba, Tsukuba 305-8571, Japan \\ ${ }^{3}$ Photovoltaic Materials Unit, National Institute for Materials Science (NIMS), Tsukuba 305-0047, Japan
}

Correspondence should be addressed to Yutaka Moritomo, moritomo@sakura.cc.tsukuba.ac.jp

Received 9 April 2012; Accepted 17 May 2012

Academic Editor: Saulius Juodkazis

Copyright (C) 2012 Kouhei Yonezawa et al. This is an open access article distributed under the Creative Commons Attribution License, which permits unrestricted use, distribution, and reproduction in any medium, provided the original work is properly cited.

Bulk heterojunction (BHJ) based on a donor (D) polymer and an acceptor (A) fullerene derivative is a promising organic photovoltaics (OPV). In order to improve the incident photon-to-current efficiency (IPCE) of the BHJ solar cell, a comprehensive understanding of the ultrafast dynamics of excited species, such as singlet exciton $\left(\mathrm{D}^{*}\right)$, interfacial charge-transfer (CT) state, and carrier $\left(\mathrm{D}^{+}\right)$, is indispensable. Here, we performed femtosecond time-resolved spectroscopy of two prototypical BHJ blend films: poly(3-hexylthiophene) (P3HT)/[6,6]-phenyl $\mathrm{C}_{61}$-butyric acid methyl ester (PCBM) blend film and poly $\left(9,9^{\prime}\right.$-dioctylfluorene-cobithiophene) (F8T2)/[6,6]-phenyl $\mathrm{C}_{71}$-butyric acid methyl ester $\left(\mathrm{PC}_{70} \mathrm{BM}\right)$ blend film. We decomposed differential absorption spectra into fast, slow, and constant components via two-exponential fitting at respective probe photon energies. The decomposition procedure clearly distinguished photoinduced absorptions (PIAs) due to $\mathrm{D}^{*}, \mathrm{CT}$, and $\mathrm{D}^{+}$. Based on these assignments, we will compare the charge dynamics between the $\mathrm{F} 8 \mathrm{~T} 2 / \mathrm{PC}_{70} \mathrm{BM}$ and $\mathrm{P} 3 \mathrm{HT} / \mathrm{PCBM}$ blend films.

\section{Introduction}

Organic photovoltaics (OPV) is an environmentally friendly and low-cost technology, which converts the solar energy into electric one. The incident photon-to-current efficiency (IPCE) of the bulk heterojunction (BHJ) solar cell $[1,2]$ is governed by the three processes: (1) charge formation process at the donor (D)-acceptor (A) interface, (2) charge transport process within the organic semiconductor, and (3) charge collecting process on the $\mathrm{Al}$ and indium tin oxide (ITO) electrodes. The femtosecond time-resolved spectroscopy is one of the powerful tool to reveal the (1) charge formation dynamics, because we can trace the ultrafast dynamics of excited species, such as singlet exciton $\left(D^{*}\right)$, interfacial charge-transfer $(\mathrm{CT})$ state, and carrier $\left(\mathrm{D}^{+}\right)[3-$ 5]. The photoirradiation of the $\mathrm{D}$ polymer (A molecule) excites an electron from the highest occupied molecular orbital (HOMO) to the lowest unoccupied molecular orbital (LUMO). We call such a photoexcited D (A) state as excitons
$\mathrm{D}^{*}\left(\mathrm{~A}^{*}\right)$. The $\mathrm{D}^{*}\left(\mathrm{~A}^{*}\right)$ state migrates within the $\mathrm{D}$ domain (or A domain) to reach the D-A interface. At the interface, the charge transfer between $\mathrm{D}$ and A produces an intermediate state (CT state). The CT state consists of electrostatically bound charge pairs, where the hole is primarily localized on the D HOMO and the electron on the A LUMO. Finally, the charge separation takes place to produce free carriers $\mathrm{D}^{+}$ $\left(\mathrm{A}^{-}\right)$.

Historically, extensive spectroscopic investigations [312] have been carried out on the charge dynamics in poly(3-hexylthiophene) (P3HT)/[6,6]-phenyl $\mathrm{C}_{61}$-butyric acid methyl ester (PCBM) blend film, due to its reproducible power conservation efficiency (PCE $>5 \%[13,14]$ ). In particular, the regioregularity of P3HT, as well as the annealing process, has a significant effect on the charge dynamics of the P3HT/PCBM blend film $[4,7,8]$. Among them, Hwang et al. [4] investigated the charge dynamics in a regioregularP3HT (RR-P3HT)/PCBM blend film and proposed a twostep process for charge generation, that is, formation of 
the interfacial CT states $(<250 \mathrm{fs})$ followed by the charge separation $(=4 \mathrm{ps})$. We emphasize that their interpretation is based on the assignment of the photoinduced absorption (PIA) signals. They assigned the PIA at $1.7 \mathrm{eV}$ to the donor polaron $[15,16]$, while they did that at $1.1-1.6 \mathrm{eV}$ to the CT state. Unfortunately, the assignment of the PIAs of the RR-P3HT/PCBM blend film is still controversial. Another candidate of OPV is poly $\left(9,9^{\prime}\right.$-dioctylfluorene-cobithiophene) (F8T2)/[6,6]-phenyl $\mathrm{C}_{71}$-butyric acid methyl ester $\left(\mathrm{PC}_{70} \mathrm{BM}\right)$, because the fluorene-based copolymers, for example, F8T2, are more stable than the thiophene-based polymers, for example, $\mathrm{P} 3 \mathrm{HT}$. The solar cell using the blend film shows a PCE of $2.2-2.3 \%[17,18]$.

In this study, we investigated the charge dynamics of two prototypical blend films, that is, RR-P3HT/PCBM and F8T2/PC 70 BM blend films. In order to assign the PIA signals, we decomposed differential absorption spectra into fast, slow, and constant components via two-exponential fittings at respective probe photon energies. The decomposition procedure clearly distinguished photoinduced absorptions (PIAs) due to $\mathrm{D}^{*}, \mathrm{CT}$, and $\mathrm{D}^{+}$. We observed exciton conversion into the CT state $\left(\mathrm{D}^{*} \rightarrow \mathrm{CT}\right)$ in both the blend films. The conversion speed $(=0.7 \mathrm{ps})$ in the $\mathrm{F} 8 \mathrm{~T} 2 / \mathrm{PC}_{70} \mathrm{BM}$ blend film is nearly the same as that (=1.2 ps) in the $\mathrm{P} 3 \mathrm{HT} / \mathrm{PCBM}$ blend film.

\section{Experiment}

2.1. Film Preparation for Optical Measurements. All materials (see Figure 1) were purchased from commercially available sources and used as received. F8T2 was purchased from American Dye Source. The weight average molecular weight $\left(M_{w}\right)$, number average molecular weight $\left(M_{n}\right)$, and polydispersity $\left(M_{w} / M_{n}\right)$ were estimated to be 45000,13000 , and 3.4, respectively. RR-P3HT was purchased from Luminescence Technology Corp. The weight average molecular weight $\left(M_{w}\right)$, number average molecular weight $\left(M_{n}\right)$, and polydispersity $\left(M_{w} / M_{n}\right)$ were estimated to be 44000,22000 , and 2.0 , respectively. The fullerene derivatives, that is, PCBM and $\mathrm{PC}_{70} \mathrm{BM}$, were purchased from Solenne.

P3HT and P3HT/PCBM blend films were spin-coated on quartz substrates and annealed for $10 \mathrm{~min}$ at $110^{\circ} \mathrm{C}$. Solutions of P3HT and that of blend with 50\% PCBM by weight was prepared by dissolving the compounds in $o$-dichlorobenzene ( $20 \mathrm{mg}$ polymer in $1 \mathrm{~mL}$ solution). The thickness of the P3HT and P3HT/PCBM blend films was 129 and $234 \mathrm{~nm}$, respectively. F8T2 and $\mathrm{F} 8 \mathrm{~T} 2 / \mathrm{PC}_{70} \mathrm{BM}$ blend films were spincoated on quartz substrates and annealed for $10 \mathrm{~min}$ at $80^{\circ} \mathrm{C}$. Solutions of F8T2 and that of blend with $66 \% \mathrm{PC}_{70} \mathrm{BM}$ by weight were prepared by dissolving the compounds in $o$-dichlorobenzene (16 mg polymer in $1 \mathrm{~mL}$ solution). The thickness of the F8T2 and F8T2/PC 70 BM blend films was 87 and $89 \mathrm{~nm}$, respectively. All the film preparation and posttreatment were performed in an inert $\mathrm{N}_{2}$ atmosphere. The F8T2/PC 70 BM blend film shows a definite D/A interface $[17,19]$. The average size of the $\mathrm{PC}_{70} \mathrm{BM}$ domains is $230 \mathrm{~nm}$ in diameter.
2.2. Preparation of OPV and Characterization. The F8T2/ $\mathrm{PC}_{70} \mathrm{BM}$ OPV was fabricated in the following configuration: ITO/PEDOT: PSS (40 nm)/active layer/LiF $(1.2 \mathrm{~nm}) / \mathrm{Al}$ $(80 \mathrm{~nm})$. The patterned ITO (conductivity: $10 \Omega$ /square) glass was precleaned in an ultrasonic bath of acetone and ethanol and then treated in an ultraviolet-ozone chamber. A thin layer $(40 \mathrm{~nm})$ of PEDOT: PSS was spin-coated onto the ITO and dried at $110^{\circ} \mathrm{C}$ for $10 \mathrm{~min}$ on a hot plate in air. The substrate was then transferred to an $\mathrm{N}_{2}$ glove box and dried again at $110^{\circ} \mathrm{C}$ for $10 \mathrm{~min}$ on a hot plate. An $o$-dichlorobenzene solution of $\mathrm{F} 8 \mathrm{~T} 2: \mathrm{PC}_{70} \mathrm{BM}(1: 2$ by weight) was subsequently spin-coated onto the PEDOT:PSS surface to form the active layer. The resultant substrates were then annealed at $80^{\circ} \mathrm{C}$ for $10 \mathrm{~min}$ in an $\mathrm{N}_{2}$ glove box. Finally, LiF $(1.2 \mathrm{~nm})$ and $\mathrm{Al}(80 \mathrm{~nm})$ were deposited onto the active layer by conventional thermal evaporation at a chamber pressure lower than $5 \times 10^{-4} \mathrm{~Pa}$, which provided the devices with an active area of $2 \times 2 \mathrm{~mm}^{2}$. For comparison, we fabricated RR$\mathrm{P} 3 \mathrm{HT} / \mathrm{PCBM} \mathrm{OPV}$ in a similar procedure. An $o$-dichlorobenzene solution of RR-P3HT: PCBM ( $1: 1$ by weight) was subsequently spin-coated onto the PEDOT: PSS surface to form the active layer. The resultant substrates were then annealed at $110^{\circ} \mathrm{C}$ for $10 \mathrm{~min}$ in an $\mathrm{N}_{2}$ glove box.

The current density-voltage $(J-V)$ curves were measured using an ADCMT 6244 DC voltage current Source/ Monitor under AM 1.5 solar-simulated light irradiation of $100 \mathrm{mWcm}^{-2}$ (Wacom Electric Co., Ltd.). The incident photon-to-current conversion efficiency (IPCE) was measured using a CEP-2000 system (Bunkoh-Keiki Co., Ltd.).

\subsection{Time-Resolved Spectroscopy. Ultrafast time-resolved spec-} troscopy was carried out in a pump-probe configuration at room temperature (Figure 2). We employed a regenerative amplified Ti: sapphire laser with a pulse width of $100 \mathrm{fs}$ and a repetition rate of $1000 \mathrm{~Hz}$ as the light source. The pump pulse wavelength was $400 \mathrm{~nm}$, which was generated as second harmonics in a $\beta-\mathrm{BaB}_{2} \mathrm{O}_{4}$ (BBO) crystal. The excitation intensity was $27-54 \mu \mathrm{J} / \mathrm{cm}^{2}$. The frequency of the pump pulse was decreased by half $(500 \mathrm{~Hz})$ to provide "pumpon" and "pump-off" condition. A white probe pulse (450$1600 \mathrm{~nm}$ ), generated by self-phase modulation in a sapphire plate, was focused on the sample with the pump pulse. Spot sizes of the pump and probe pulses were 2.5 and $1.3 \mathrm{~mm}$ in diameter, respectively. The transmitted probe spectra were detected using a $72 \mathrm{ch}$ Si photodiode array $(450-900 \mathrm{~nm})$ and/or a $256 \mathrm{ch}$ InGaAs photodiode array $(800-1600 \mathrm{~nm})$ attached to a $30 \mathrm{~cm}$ imaging spectrometer. The spectral data were accumulated for 10000 pulses to improve the signal/noise ratio. The differential absorption spectra $(\Delta \mathrm{OD})$ are expressed as $\Delta \mathrm{OD}=-\ln \left(I_{\text {on }} / I_{\text {off }}\right)$, where $I_{\text {on }}$ and $I_{\text {off }}$ are the transmitted light intensity with and without pump excitation, respectively.

2.4. Optical Modulation Spectroscopy. Optical modulation spectroscopy was carried out in a pump-probe configuration at room temperature (Figure 3). A continuous wave Yttrium Aluminum Garnet (CW-YAG) laser $(532 \mathrm{~nm})$ was used as the excitation light source. The excitation intensity was 


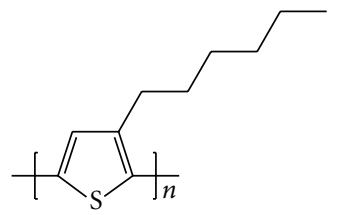

P3HT

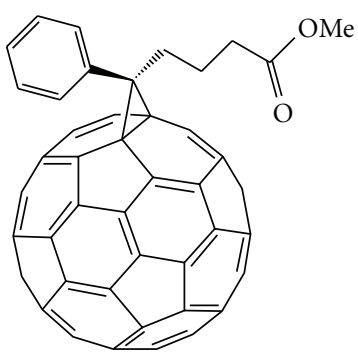

PCBM

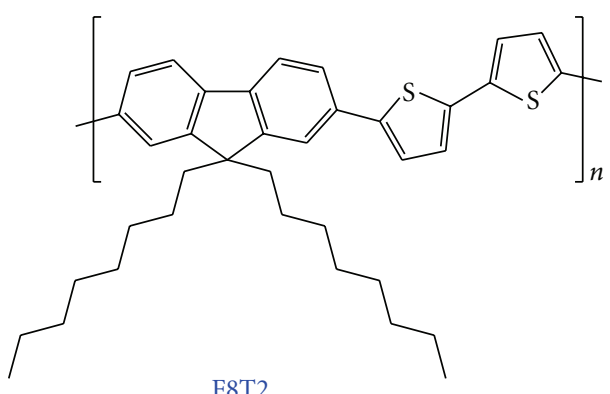

F8T2

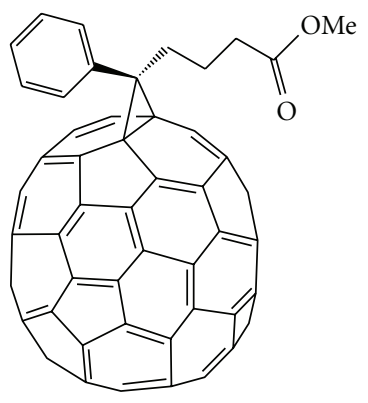

$\mathrm{PC}_{70} \mathrm{BM}$

FIGURE 1: Molecular structures of poly(3-hexylthiophene) (P3HT), poly(9,9'-dioctylfluorene-co-bithiophene) (F8T2), [6,6]-phenyl $\mathrm{C}_{61}$ butyric acid methyl ester (PCBM), and $[6,6]$-phenyl $\mathrm{C}_{71}$-butyric acid methyl ester $\left(\mathrm{PC}_{70} \mathrm{BM}\right)$.

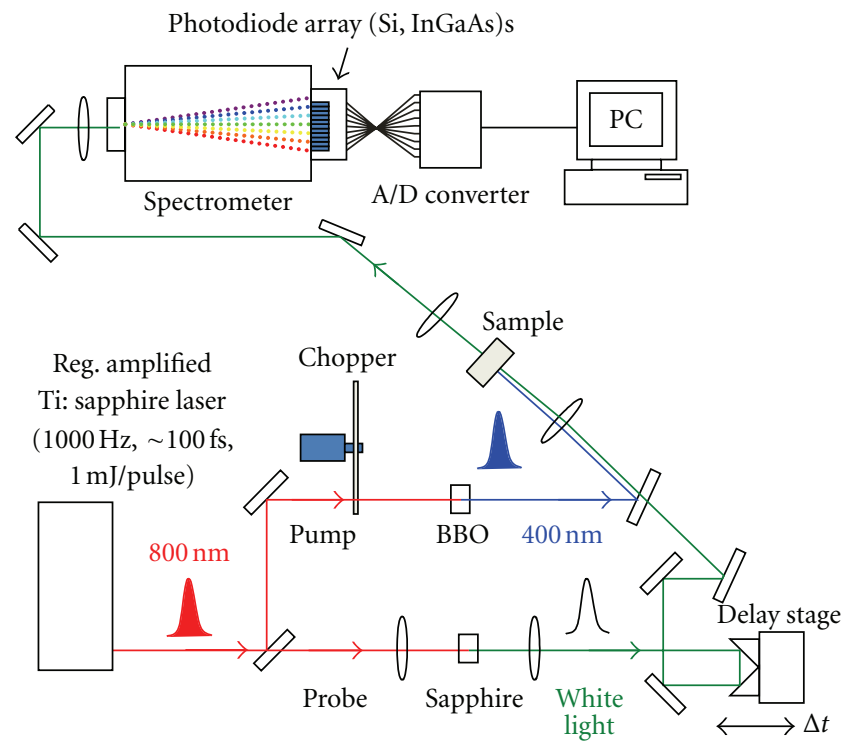

FIGURE 2: Schematic illustration of the experimental setup for timeresolved spectroscopy.

$1.4 \mathrm{~mW} / \mathrm{cm}^{2}$, which was modulated with an optical chopper. The white light from the Halogen and/or Xe lamp was monochromatized with a $30 \mathrm{~cm}$ imaging spectrometer. The monochromatic probe light was focused on the sample with the pump light. The transmitted probe light was detected using a $\mathrm{Si}$ and/or InGaAs photodiode. A lock-in detection was adopted to extract the modulation signal. The optical modulation spectroscopy can clarify the PIA due to the longlived $\mathrm{D}^{+}$.

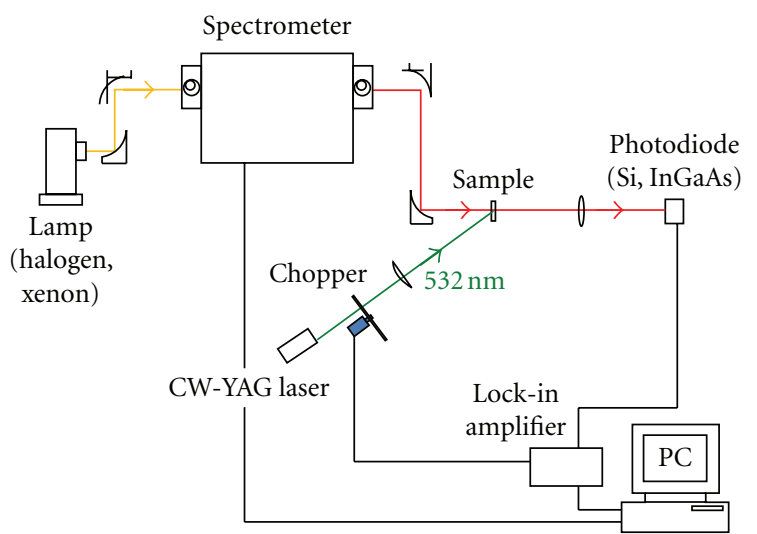

FIGURE 3: Schematic illustration of the experimental setup for optical modulation spectroscopy.

\section{Results}

3.1. OPV Properties of RR-P3HT/PCBM and F8T2/PC ${ }_{70} B M$ Blend Films. Figure 4(a) shows current density-voltage $(J-V)$ curves of OPVs based on the RR-P3HT/PCBM and F8T2/ $\mathrm{PC}_{70} \mathrm{BM}$ blend films. The OPV based on F8T2 (HOMO of $-5.46 \mathrm{eV})$ exhibits a high open-circuit voltage $\left(V_{\mathrm{oc}}\right)$ of $1.00 \mathrm{~V}$, as compared with the value $(=0.6 \mathrm{~V})$ in typical OPVs based on RR-P3HT (HOMO of $-4.70 \mathrm{eV}$ ). This is because $V_{\text {oc }}$ is basically determined by the energy difference between D HOMO level and A LUMO $(\sim-3.7 \mathrm{eV})$. The OPV based on the $\mathrm{F} 8 \mathrm{~T} 2 / \mathrm{PC}_{70} \mathrm{BM}$ blend film exhibits a short circuit current $\left(J_{\text {sc }}\right)$ of $4.28 \mathrm{mAcm}^{-2}$, a $V_{\text {oc }}$ of $1.00 \mathrm{~V}$, a fill factor $(\mathrm{FF})$ 


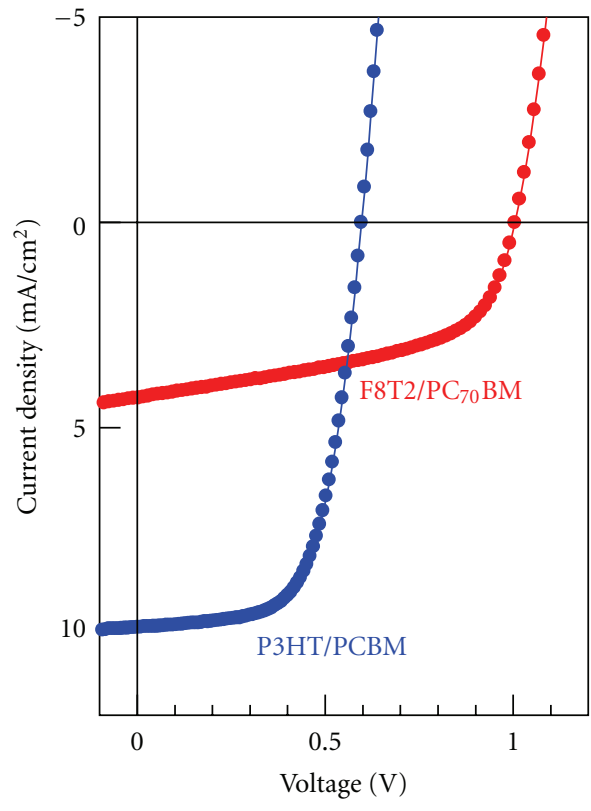

(a)

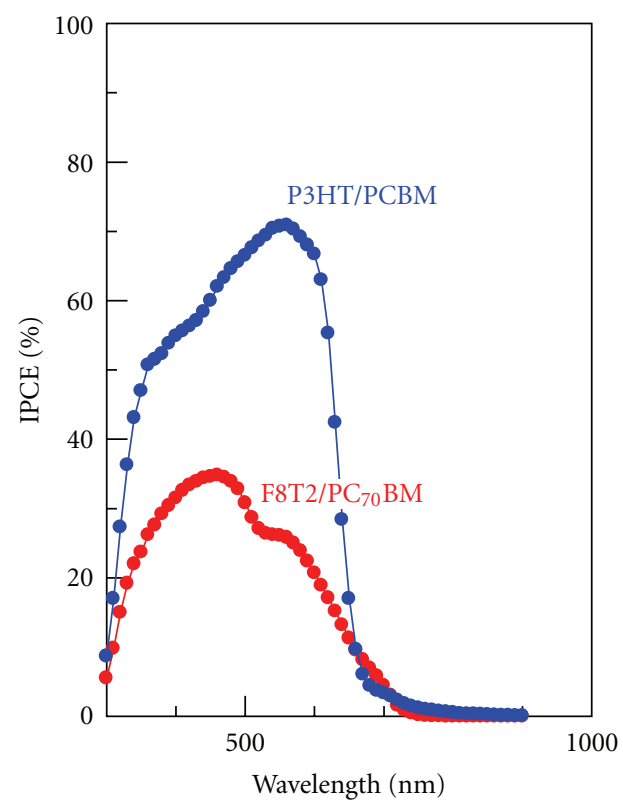

(b)

Figure 4: (a) $J$ - $V$ curves of OPVs based on the RR-P3HT/PCBM and F8T2/PC 70 BM blend films. (b) IPCE spectra for OPVs based on the RR-P3HT/PCBM and F8T2/PC 70 BM blend films.
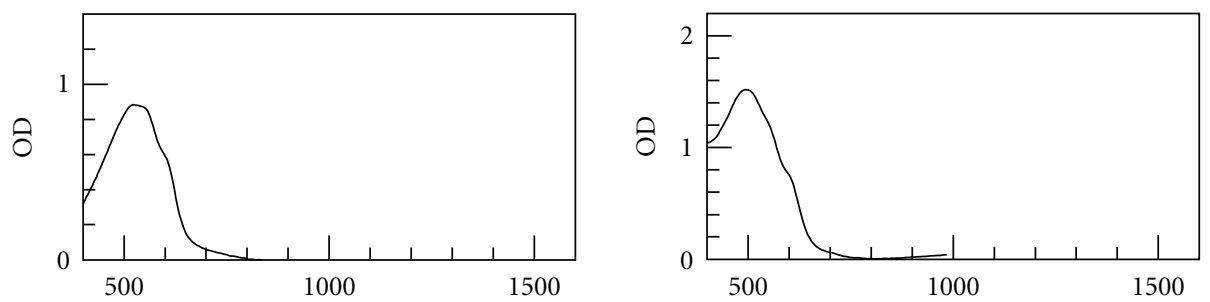

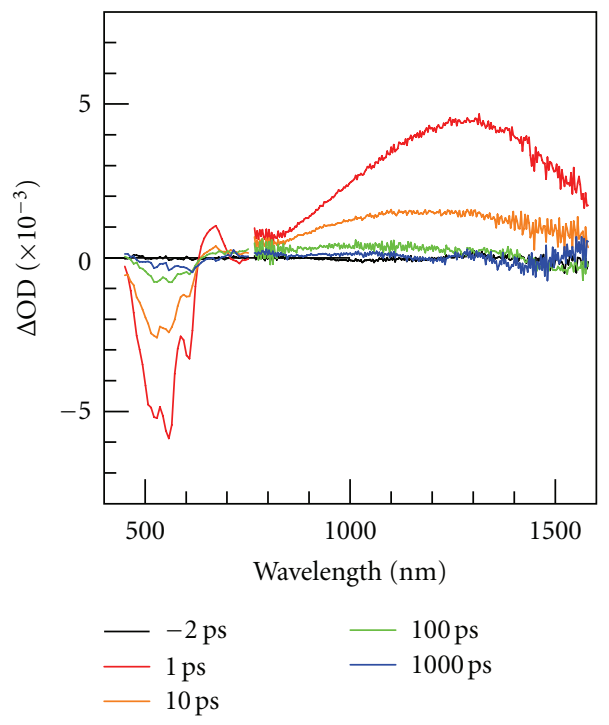

(a) RR-P3HT

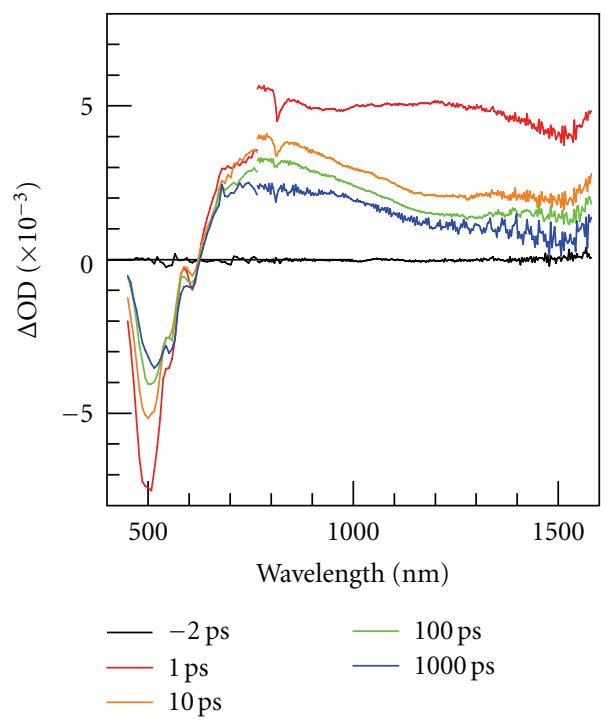

(b) RR-P3HT/PCBM

FIgure 5: Absorption (OD) spectra and differential absorption ( $\triangle \mathrm{OD}$ ) spectra of (a) neat RR-P3HT film and (b) RR-P3HT/PCBM blend films at $300 \mathrm{~K}$. 

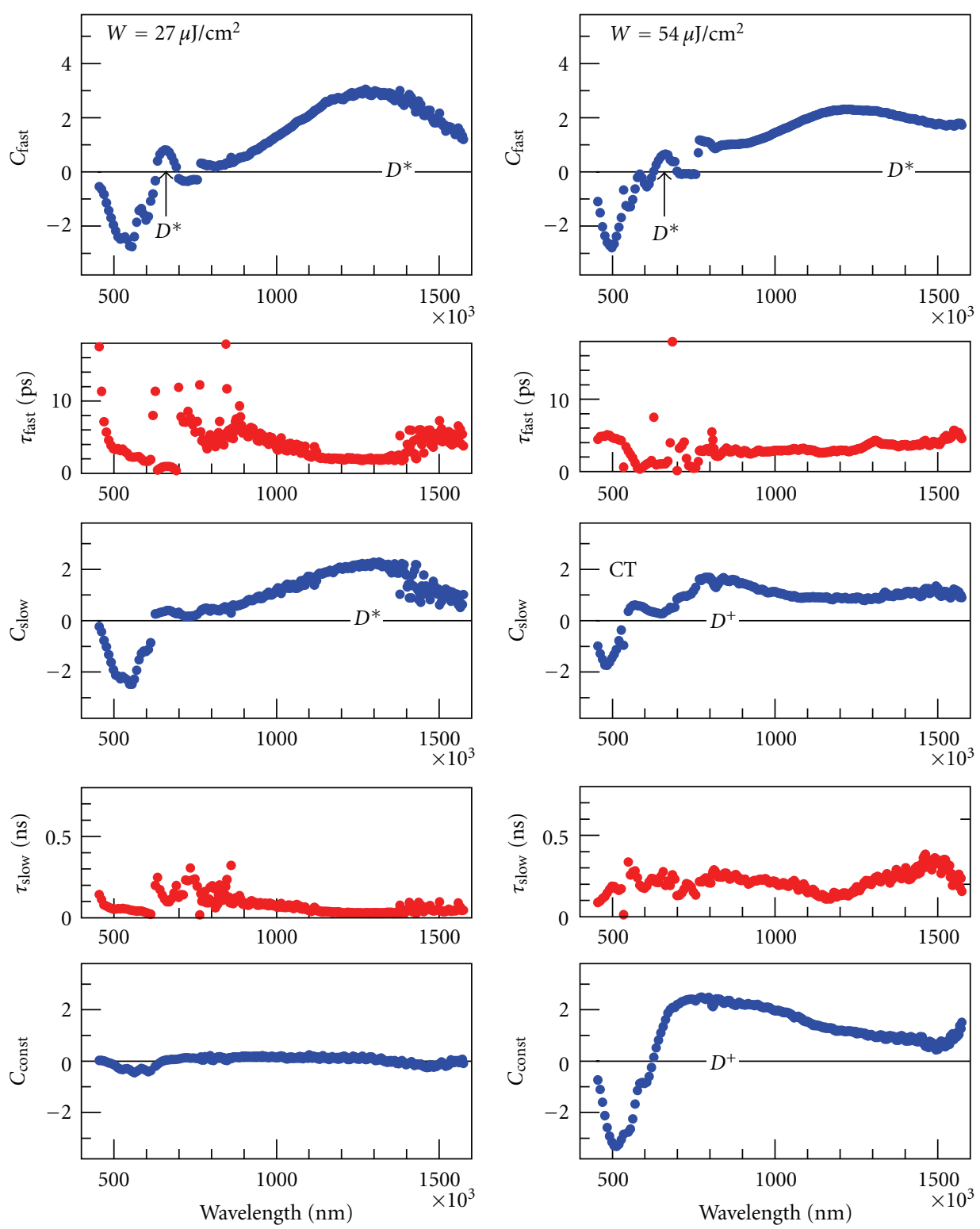

(a) RR-P3HT

(b) RR-P3HT/PCBM

FIGURE 6: Decomposition of the time-resolved spectra of (a) neat RR-P3HT film and (b) RR-P3HT/PCBM blend films. The upper two panels are magnitudes $\left(C_{\text {fast }}\right)$ and lifetimes $\left(\tau_{\text {fast }}\right)$ of the fast component. The middle two panels are magnitudes $\left(C_{\text {slow }}\right)$ and lifetimes $\left(\tau_{\text {slow }}\right)$ of the slow component. The bottom panels are magnitudes $\left(C_{\text {const }}\right)$ of the constant component. $\mathrm{D}^{*}, \mathrm{CT}$, and $\mathrm{D}^{+}$represent PIAs due to singlet exciton, CT state, and carrier, respectively.

of 0.53 , and a PCE of 2.28\%. The OPV based on the RRP3HT/PCBM blend film exhibits a $J_{\text {sc }}$ of $9.9 \mathrm{mAcm}^{-2}$, a $V_{\text {oc }}$ of $0.60 \mathrm{~V}, \mathrm{a}, \mathrm{FF}$ of 0.64 , and a PCE of $3.8 \%$.

Figure 4(b) shows wavelength dependence of the photovoltaic response for the OPVs based on the RR-P3HT/PCBM and F8T2/PCBM blend films. In all the wavelength region, the IPCE values for the F8T2/PCBM blend film are smaller than those for the RR-P3HT/PCBM blend film. The IPCE values at $400 \mathrm{~nm}$ are $54 \%$ and $30 \%$ for the RR-P3HT/PCBM and F8T2/PCBM blend films, respectively.

3.2. Time-Resolved Spectra of RR-P3HT and RR-P3HT/PCBM Films. Figure 5 shows $\triangle \mathrm{OD}$ spectra (lower panels) of (a) neat
RR-P3HT film and (b) RR-P3HT/PCBM blend films, together with their linear absorption spectra (OD: upper panels). As seen in the OD spectra, the pump pulse (at $400 \mathrm{~nm}$ ) efficiently excites the D polymer. In all the films, the $\triangle \mathrm{OD}$ spectra consist of negative signals in the shortwavelength region and positive signals in the long-wavelength region. The negative signal is ascribed to the ground state bleach (GSB) as well as the stimulated emission (SE) of singlet exciton luminescence. On the other hand, the positive signal is ascribed to PIAs due to the photogenerated species, such as $\mathrm{D}^{*}, \mathrm{CT}$, and $\mathrm{D}^{+}$.

Generally speaking, the lifetime is a good physical quantity that distinguishes the PIAs due to different excited 

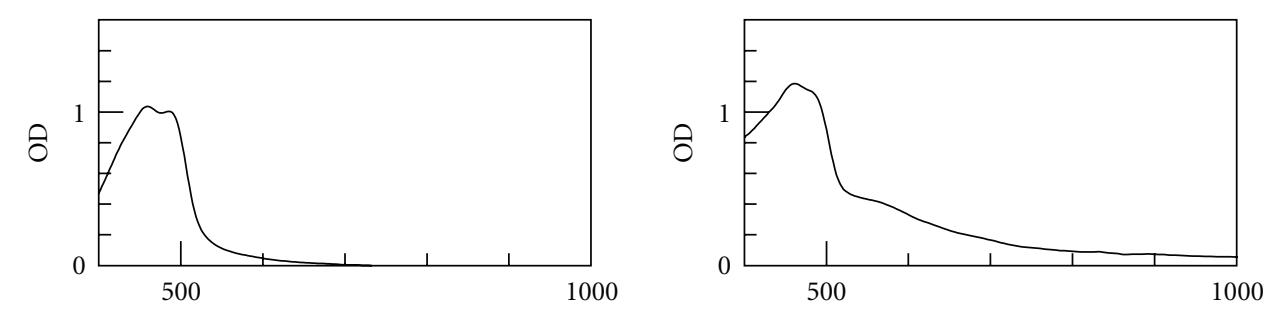

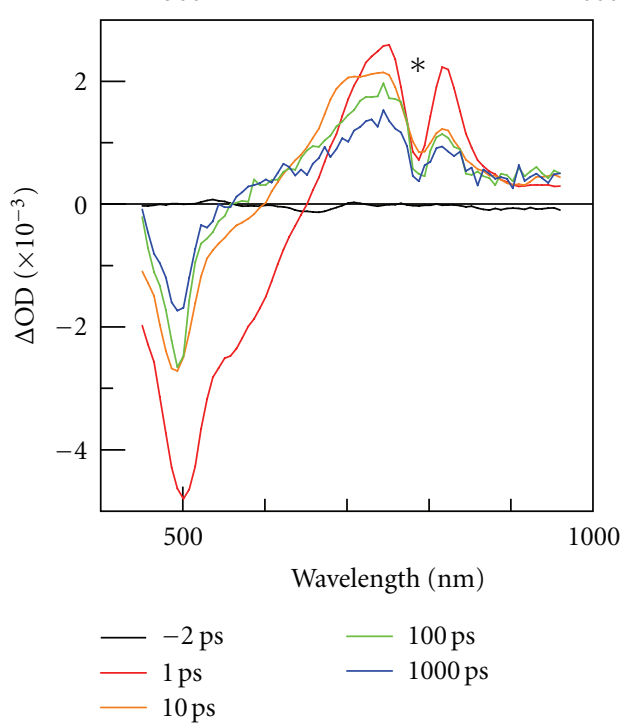

(a) F8T2

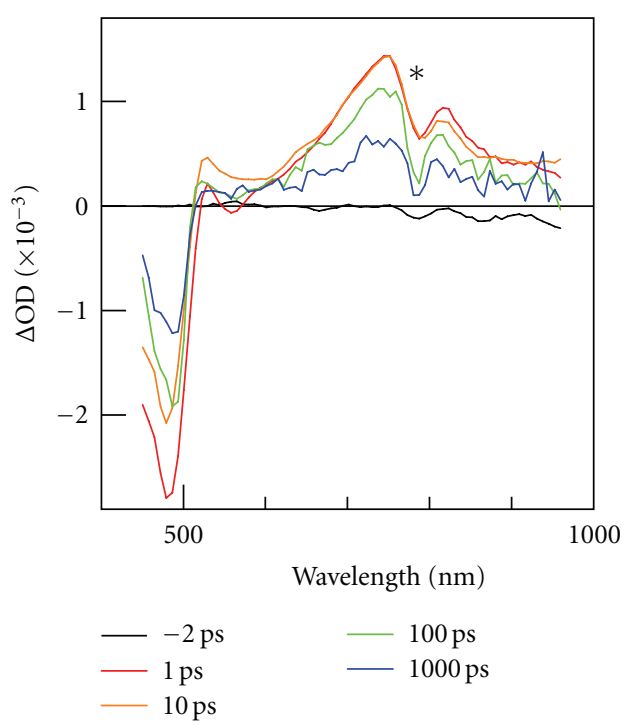

(b) $\mathrm{F} 8 \mathrm{~T} 2 / \mathrm{PC}_{70} \mathrm{BM}$

Figure 7: Absorption (OD) spectra and differential absorption ( $\triangle \mathrm{OD}$ ) spectra of (a) neat F8T2 film and (b) F8T2/PC 70 BM blend films at $300 \mathrm{~K}$. Star symbols indicate an artificial structure due to the notch filter at $800 \mathrm{~nm}$.

species: for example, lifetime of $\mathrm{D}^{*}$ is much faster than that of $\mathrm{D}^{+}$. In order to decompose the time-resolved spectra into fast, slow and constant components, we analyzed the decay curve at respective probe photon energies with two exponential functions:

$$
\Delta \mathrm{OD}=C_{\text {fast }} \times \exp \left(-\frac{t}{\tau_{\text {fast }}}\right)+C_{\text {slow }} \times \exp \left(-\frac{t}{\tau_{\text {slow }}}\right)+C_{\text {const }},
$$

where $C_{\text {fast }}\left(\tau_{\text {fast }}\right), C_{\text {slow }}\left(\tau_{\text {slow }}\right)$, and $C_{\text {const }}$ are the magnitude (lifetime) of the respective components [20]. Thus obtained parameters, $C_{\text {fast }}, \tau_{\text {fast }}, C_{\text {slow }}, \tau_{\text {slow }}$, and $C_{\text {const }}$ are plotted in Figure 6 against wavelength.

Figure 6(a) shows the spectral components of the neat P3HT film. In the $C_{\text {fast }}$ component, a negative peak around $550 \mathrm{~nm}$ is ascribed to the GSB and SE. On the other hand, a positive sharp signal at $650 \mathrm{~nm}$ and broad signal at $\sim 1300 \mathrm{~nm}$ are ascribed to the PIA due to $\mathrm{D}^{*}$. In the $C_{\text {slow }}$ component, the broad PIA due to $\mathrm{D}^{*}$ is discernible at $\sim 1300 \mathrm{~nm}$. No signal is observed in the $C_{\text {slow }}$ component.

Figure 6(b) shows the spectral components of the RRP3HT/PCBM blend film. In the $C_{\text {fast }}$ component, the spectral profile is almost the same as the neat RR-P3HT film: negative signal due to GSB and SE at $500 \mathrm{~nm}$ and PIAs due to $\mathrm{D}^{*}$ at $650 \mathrm{~nm}$ and $\sim 1300 \mathrm{~nm}$. In the $C_{\text {slow }}$ component, the PIA due to $\mathrm{D}^{*}$ completely disappears and new PIAs appears at $570 \mathrm{~nm}$ and $\sim 800 \mathrm{~nm}$. In the $C_{\text {const }}$ component, broad PIA at $\sim 700 \mathrm{~nm}$ is observed. Jiang et al. [16] performed optical modulation spectroscopy in the neat RR-P3HT film and observed polaron signals at $\sim 670 \mathrm{~nm}$ and $\sim 1000 \mathrm{~nm}$. They ascribed the former and latter signals to the free and localized carriers, respectively. According to their assignments, we ascribed the PIAs at $\sim 700 \mathrm{~nm}\left(C_{\text {const }}\right)$ and at $\sim 800 \mathrm{~nm}\left(C_{\text {slow }}\right)$ to the free and localized carriers, respectively. Based on the assignments of PIAs in the F8T2/PC ${ }_{70} \mathrm{BM}$ blend film, we ascribed the PIA at $570 \mathrm{~nm}\left(C_{\text {slow }}\right)$ to the CT state (vide infra).

3.3. Time-Resolved Spectra of F8T2 and F8T2/PC 70 BM Films. Figure 7 shows $\triangle$ OD spectra (lower panels) of (a) neat F8T2 film and (b) $\mathrm{F} 8 \mathrm{~T} 2 / \mathrm{PC}_{70} \mathrm{BM}$ blend films, together with the OD spectra (upper panels). As seen in the OD spectra, the pump pulse (at $400 \mathrm{~nm}$ ) efficiently excites the D polymer. In all the films, the $\Delta \mathrm{OD}$ spectra consist of negative signals in the short-wavelength region and positive signals in the long-wavelength region. The negative signal is ascribed to GSB and/or SE. On the other hand, the positive signal is ascribed to PIAs due to the photo-generated species, such as $\mathrm{D}^{*}, \mathrm{CT}$, and $\mathrm{D}^{+}$. We analyzed the decay curve at respective probe photon energies with two exponential functions (1). Obtained parameters $C_{\text {fast }}, \tau_{\text {fast }}, C_{\text {slow }}, \tau_{\text {slow }}$, and $C_{\text {const }}$ are plotted in Figure 8 against wavelength.

Figure 8(a) shows the spectral components of the neat F8T2 film. In the $C_{\text {fast }}$ component, a negative peak at $506 \mathrm{~nm}$ are ascribed to the GSB, whereas a negative peak at $553 \mathrm{~nm}$ 

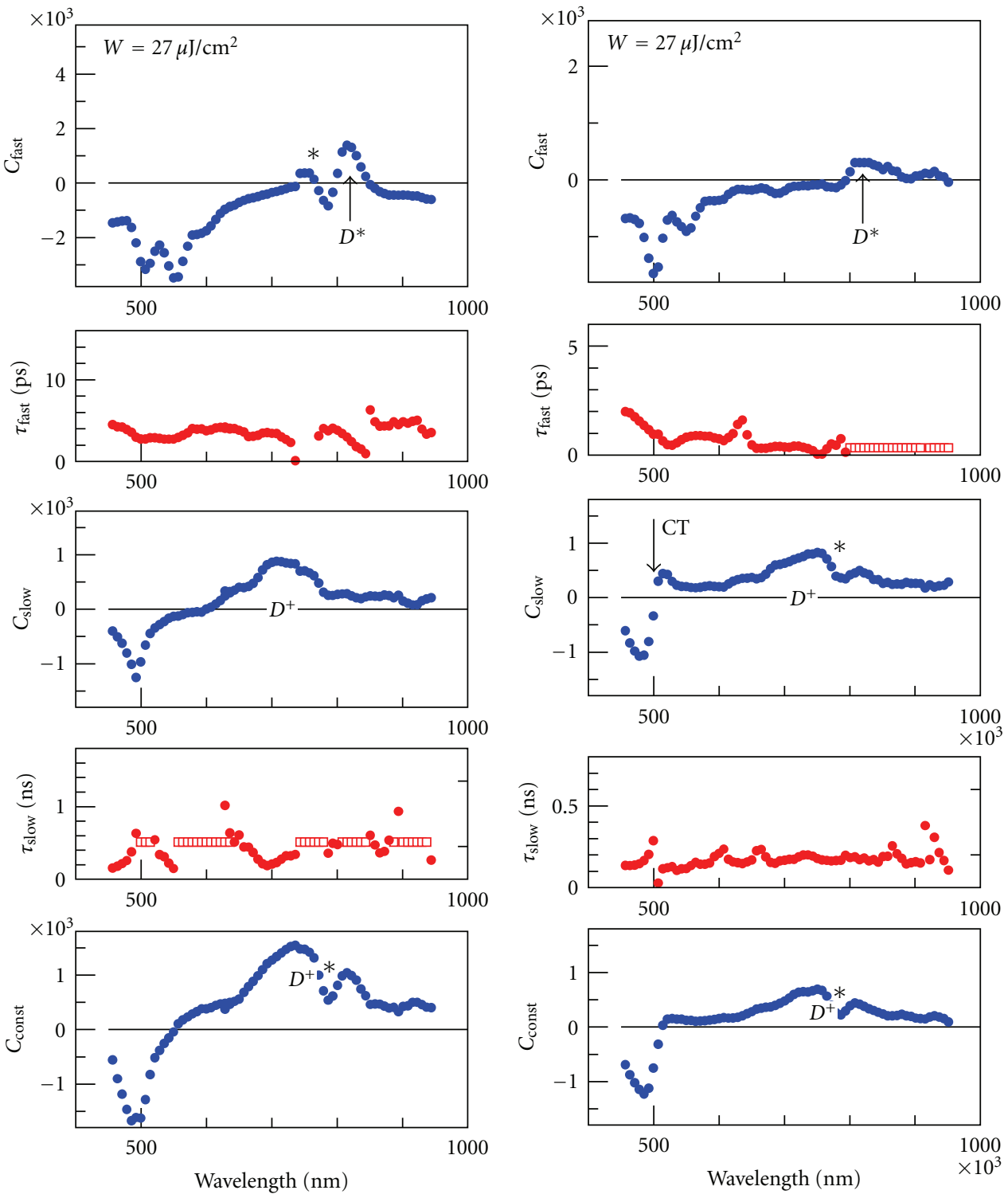

(a) $\mathrm{F} 8 \mathrm{~T} 2$

(b) $\mathrm{F} 8 \mathrm{~T} 2 / \mathrm{PC}_{70} \mathrm{BM}$

FIGURE 8: Decomposition of the time-resolved spectra of (a) neat F8T2 film and (b) F8T2/PC 70 BM blend films. The upper two panels are magnitudes $\left(C_{\text {fast }}\right)$ and lifetimes $\left(\tau_{\text {fast }}\right)$ of the fast component. The middle two panels are magnitudes $\left(C_{\text {slow }}\right)$ and lifetimes $\left(\tau_{\text {slow }}\right)$ of the slow component. The bottom panels are magnitudes $\left(C_{\text {const }}\right)$ of the constant component. Open symbols indicate that the parameter is fixed in the fitting procedure. Star symbols indicate artificial structures due to the notch filter at $800 \mathrm{~nm}$. D*, CT, and $\mathrm{D}^{+}$represent PIAs due to singlet exciton, CT state, and carrier, respectively.

and the broad background extending from 500 to $700 \mathrm{~nm}$ is ascribed to the SE. Actually, the luminescence spectra of the F8T2 film extend from 500 to $700 \mathrm{~nm}$ with a peak at $550 \mathrm{~nm}$. [21] On the other hand, a positive sharp signal around $800 \mathrm{~nm}$ is ascribed to the PIA due to $\mathrm{D}^{*}$. Actually, the exciton lifetime $(=2.7 \mathrm{ps})$ is comparable to the decay time $(\sim 3 \mathrm{ps})$ of the SE signal. In the $C_{\text {slow }}$ component, a positive broad signal is observed at $\sim 700 \mathrm{~nm}$. We ascribed the signal to the PIA due to $\mathrm{D}^{+}$, because a long-lived polaron signal was observed at $\sim 800 \mathrm{~nm}$ in the optical modulation spectrum of the $\mathrm{F} 8 \mathrm{~T} 2 / \mathrm{PC}_{70} \mathrm{BM}$ blend film (see Figure $9)$.
Figure 8(b) shows the spectral component of the F8T2/ $\mathrm{PC}_{70} \mathrm{BM}$ blend film. In the $C_{\text {fast }}$ component, the GSB signal is observed at $501 \mathrm{~nm}$, whereas the SE signal $(500-700 \mathrm{~nm})$ is rather suppressed. The suppression of the SE signal is probably due to the doping-induced luminescence quenching [21]. The PIA due to $\mathrm{D}^{*}$ is discernible at $800 \mathrm{~nm}$. In the $C_{\text {slow }}$ component, the PIA due to $\mathrm{D}^{*}$ completely disappears and new PIAs appears at $520 \mathrm{~nm}$ and $\sim 700 \mathrm{~nm}$. The PIA at $\sim 700 \mathrm{~nm}$ is due to $\mathrm{D}^{+}$, because a long-lived carrier'signal was observed at $\sim 800 \mathrm{~nm}$ in the optical modulation spectrum of the F8T2/PC 70 BM blend film (see Figure 9). For the following reason, we ascribed the $520 \mathrm{~nm}$ signal to the PIA 


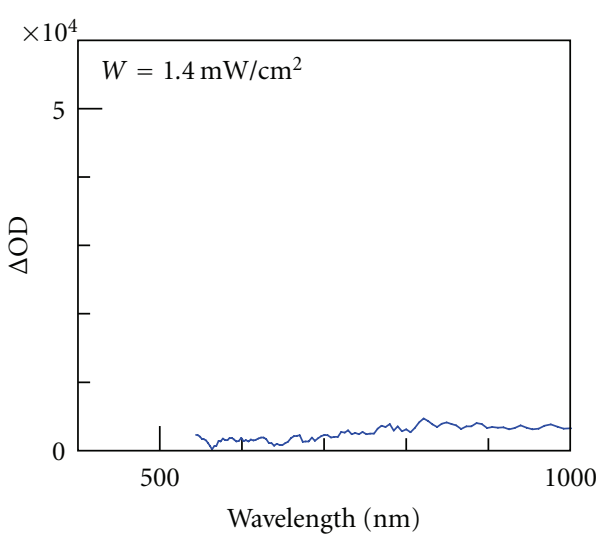

(a) $\mathrm{F} 8 \mathrm{~T} 2$

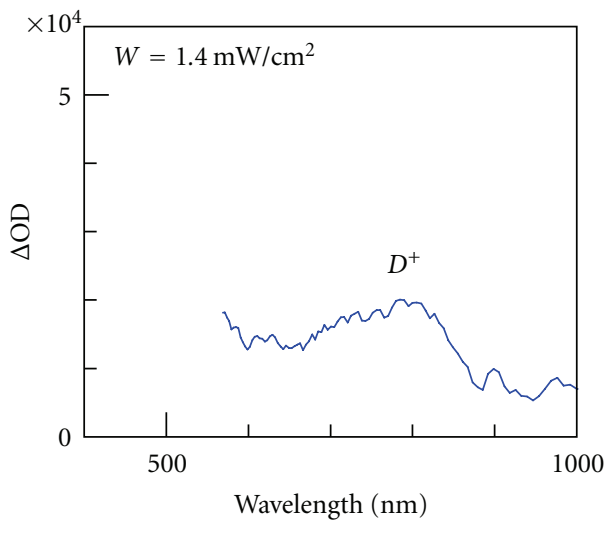

(b) $\mathrm{F} 8 \mathrm{~T} 2 / \mathrm{PC}_{70} \mathrm{BM}$

FIGURE 9: Optical modulation spectra of (a) neat F8T2 film and (b) F8T2/PC 70 BM blend films.

due to the CT state. We compared the $C_{\text {slow }}$ component in the $1: 3$ blend film (not shown) with that of the $1: 2$ film [19]. The average size of the $\mathrm{PC}_{70} \mathrm{BM}$ domains is $300 \mathrm{~nm}$ $(230 \mathrm{~nm})$ in diameter in the $1: 3(1: 2)$ blend film: the interface region is much reduced in the $1: 3$ film. We found that the $520 \mathrm{~nm}$ signal is suppressed in the $1: 3 \mathrm{film}$, suggesting that the $520 \mathrm{~nm}$ signal relates to the interface. In addition, Lim et al. [21] reported an extra $570 \mathrm{~nm}$ absorption in the F8T2 film, in which 8\% 2,3,5,6-tetrafluoro-7,7,8,8-tetracyanoquinodimethane $\left(\mathrm{F}_{4} \mathrm{TCNQ}\right)$ is doped as an oxidant. They ascribed the $570 \mathrm{~nm}$ absorption to a CT complex, that is, $\mathrm{F}_{8} \mathrm{~T}_{2}{ }^{+}-\mathrm{F}_{4} \mathrm{TCNQ}^{-}$. Analogously, the $\mathrm{CT}$ state, that is, $\mathrm{F} 8 \mathrm{~T}^{+}{ }^{+}-\mathrm{PC}_{70} \mathrm{BM}^{-}$, in our blend film is responsible for the PIA at $520 \mathrm{~nm}$. In the $C_{\text {slow }}$ component, PIA due to the CT state disappears, and only the PIA due to $\mathrm{D}^{+}$is observed.

Here, we note that the energy position and temporal behavior of the PIA at $570 \mathrm{~nm}$ in the RR-P3HT/PCBM blend film are analogues to the PIA at $570 \mathrm{~nm}$ in the F8T2/PC 70 BM blend film. This strongly suggests that the PIA at $570 \mathrm{~nm}$ in the $\mathrm{F} 8 \mathrm{~T} 2 / \mathrm{PC}_{70} \mathrm{BM}$ blend film is also ascribed to the $\mathrm{CT}$ state.

3.4. Optical Modulation Spectra of F8T2 and F8T2/PC $C_{70} B M$ Films. Figure 9 shows optical modulation spectra of (a) F8T2 and (b) F8T2/PC $70 \mathrm{BM}$ blend films. No signal is observed in the neat F8T2 film. In the F8T2/PC ${ }_{70} \mathrm{BM}$ blend film, characteristic positive signal is observed at $\sim 800 \mathrm{~nm}$ due to the long-lived carriers. Consistently, Ravirajan et al. [22] re-ported positive polaron signal at $720 \mathrm{~nm}$ in the chemically oxidized F8T2.

\section{Discussions}

Figure 10 shows temporal evolution of the PIAs of RRP3HT/PCBM blend film due to $\mathrm{D}^{*}$, CT state, and $\mathrm{D}^{+}$. Solid curves are the results of least-squares fitting with (1). The exciton lifetime ( $\tau_{\text {fast }}=0.9 \mathrm{ps}$ ) is close to the formation time $\left(\tau_{\text {fast }}=1.2 \mathrm{ps}\right)$ of the CT state, indicating exciton conversion into the CT state $\left(D^{*} \rightarrow C T\right)$. The finite rise time of the CT state suggests that the state is created by exciton conversion at the interface, rather than by direct photo-generation. On the other hand, the PIA due to $\mathrm{D}^{+}$exhibits a monotonic decrease with time, implying that $\mathrm{D}^{+}$is created mainly by direct photogeneration, not by conversion from the $\mathrm{CT}$ state. The number of $\mathrm{D}^{+}$gradually decreases and becomes $65 \%$ of the initial state at $\sim 1 \mathrm{~ns}$. Note that the apparent constant component of $660 \mathrm{~nm}$ and at $560 \mathrm{~nm}$ should be ascribed to the broad PIA due to $\mathrm{D}^{+}$and GSB, respectively.

Figure 11 shows temporal evolution of the PIAs of F8T2/ $\mathrm{PC}_{70} \mathrm{BM}$ blend film due to $\mathrm{D}^{*}, \mathrm{CT}$ state, and $\mathrm{D}^{+}$. Solid curves are the results of least-squares fitting with (1). The exciton lifetime $\left(\tau_{\text {fast }}=2.0 \mathrm{ps}\right)$ is close to the formation time $\left(\tau_{\text {fast }}=\right.$ $0.7 \mathrm{ps}$ ) of the CT state, indicating exciton conversion into the CT state $\left(D^{*} \rightarrow C T\right)$. The finite rise time of the CT state suggests that the state is created by exciton conversion at the interface, rather than by direct photo-generation. On the other hand, the PIA due to $\mathrm{D}^{+}$exhibits a monotonic decrease with time, implying that $\mathrm{D}^{+}$is created mainly by direct photo-generation, not by conversion from the CT state. The number of $\mathrm{D}^{+}$gradually decreases and becomes $40 \%$ of the initial state at $\sim 1 \mathrm{~ns}$. Note that the apparent constant component of $800 \mathrm{~nm}$ should be ascribed to the broad PIA due to $\mathrm{D}^{+}$.

Finally, let us comment on the plasmonic enhancement effect, which is a key technique to design the highly efficient OPV. For example, Poh et al. [23] clearly demonstrated that gold nanoparticles on the PEDOT-PSS enhance the PCE of the bilayer P3HT- $\mathrm{C}_{60}$ device. They ascribed the enhancement to the enhanced absorption based on a finite-difference time-domain method (FDTD) simulation. We suspect that existence of the metal nanoparticle significantly influences the charge formation dynamics itself via the strong local field around the metal nanoparticles, especially when they locate near the D-A interface. We emphasize that the ultrafast spectroscopy is a powerful tool to clarify the plasmonic effects on the charge formation dynamics.

\section{Summary}

We investigated the charge dynamics of two prototypical blend films, that is, RR-P3HT/PCBM and F8T2/PC $70 \mathrm{BM}$ 


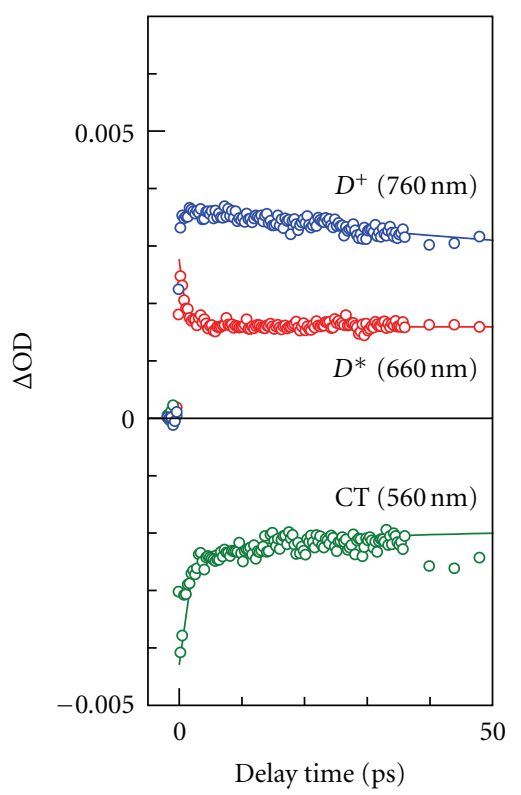

(a) RR-P3HT/PCBM

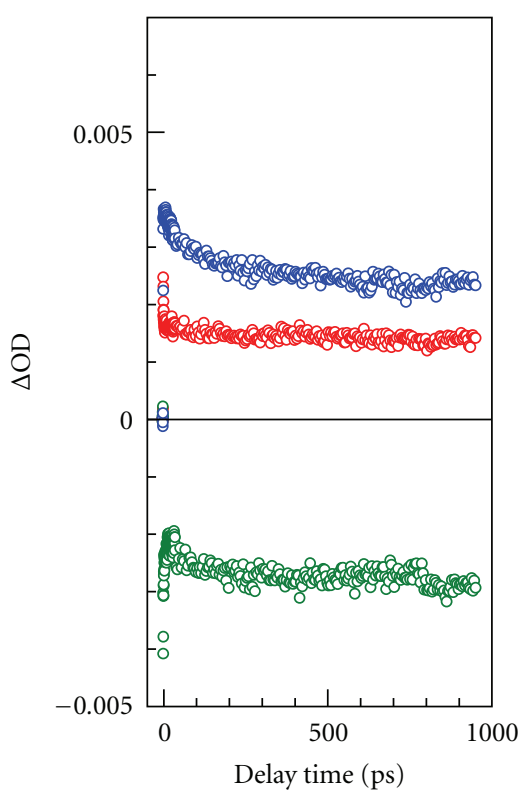

(b) RR-P3HT/PCBM

FIgURE 10: Temporal evolutions of PIAs of RR-P3HT/PCBM blend film due to $\mathrm{D}^{*}$, CT state, and $\mathrm{D}^{+}$: (a) fast region and (b) slow region. Solid curves in (a) are results of least-squares fitting with exponential functions: $\Delta \mathrm{OD}=C_{\text {fast }} \times \exp \left(-t / \tau_{\text {fast }}\right)+C_{\text {slow }} \times \exp \left(-t / \tau_{\text {slow }}\right)+C_{\text {const }}, C_{\text {fast }}$ is fixed at 0 in the PIA due to $\mathrm{D}^{+}$.

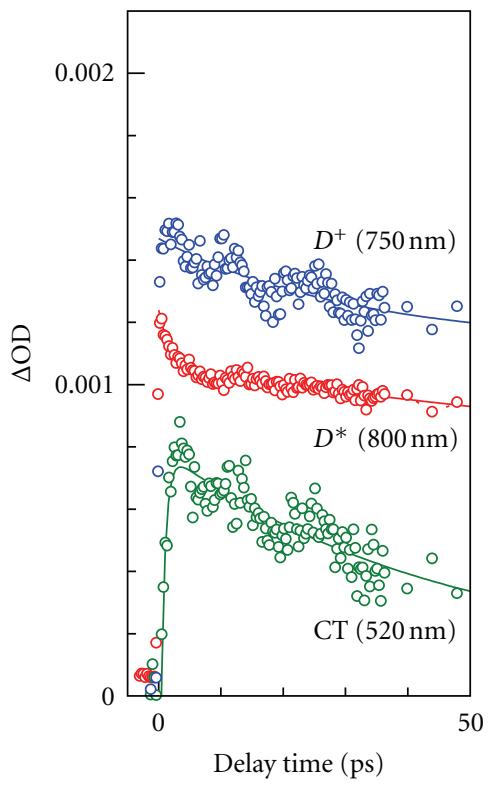

(a) $\mathrm{F} 8 \mathrm{~T} 2 / \mathrm{PC}_{70} \mathrm{BM}$

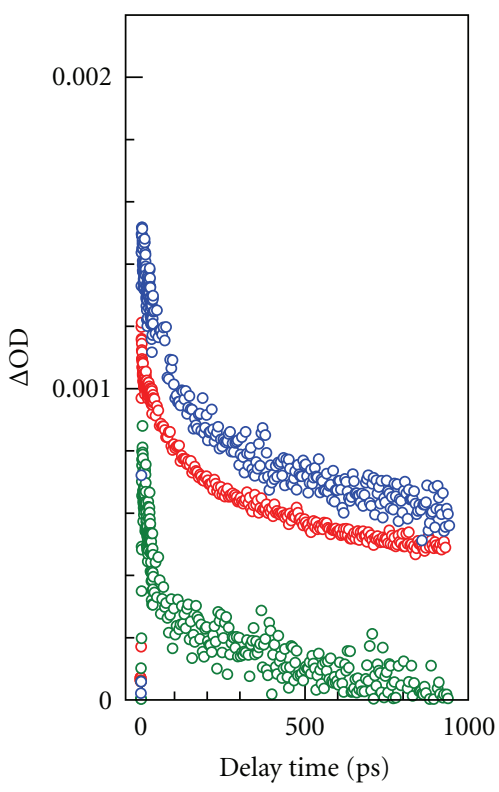

(b) $\mathrm{F} 8 \mathrm{~T} 2 / \mathrm{PC}_{70} \mathrm{BM}$

Figure 11: Temporal evolutions of PIAs of F8T2/PC 70 BM blend film due to $\mathrm{D}^{*}$, CT state, and $\mathrm{D}^{+}$: (a) fast region and (b) slow region. Solid curves in (a) are results of least-squares fitting with exponential functions: $\Delta \mathrm{OD}=C_{\text {fast }} \times \exp \left(-t / \tau_{\text {fast }}\right)+C_{\text {slow }} \times \exp \left(-t / \tau_{\text {slow }}\right)+C_{\text {const }}, C_{\text {fast }}$ is fixed at 0 in the PIA due to $\mathrm{D}^{+}$.

blend films. We observed exciton conversion into the CT state $\left(\mathrm{D}^{*} \rightarrow \mathrm{CT}\right)$ in both the blend films. The conversion speed $(=0.7 \mathrm{ps})$ in the $\mathrm{F} 8 \mathrm{~T} 2 / \mathrm{PC}_{70} \mathrm{BM}$ blend film is nearly the same as that $(=1.2 \mathrm{ps})$ in the $\mathrm{P} 3 \mathrm{HT} / \mathrm{PCBM}$ blend film. Most of the carriers, however, are created by direct photogeneration, not by conversion from the CT state. The number of $\mathrm{D}^{+}$gradually decreases to $65 \%(40 \%)$ of the initial state at $\sim 1 \mathrm{~ns}$ in the RR-P3HT/PCBM (F8T2/PC $\left.{ }_{70} \mathrm{BM}\right)$ blend film. The faster recombination ratio perhaps causes the lower $\mathrm{PCE}$ in the $\mathrm{F} 8 \mathrm{~T} 2 / \mathrm{PC}_{70} \mathrm{BM}$ blend film. 


\section{Acknowledgment}

This work was supported by a Grant-in-Aid for Young Scientists (B) (22750176) for Scientific Research from the Ministry of Education, Culture, Sports, Science and Technology, Japan.

\section{References}

[1] M. Hiramoto, H. Fujiwara, and M. Yokoyama, "Three-layered organic solar cell with a photoactive interlayer of codeposited pigments," Applied Physics Letters, vol. 58, no. 10, pp. 10621064, 1991.

[2] N. S. Sariciftci, L. Smilowitz, A. J. Heeger, and F. Wudl, "Photoinduced electron transfer from a conducting polymer to buckminsterfullerene," Science, vol. 258, no. 5087, pp. 1474-1476, 1992.

[3] G. Grancini, D. Polli, D. Fazzi, J. Cabanillas-Gonzalez, G. Cerullo, and G. Lanzani, "Transient absorption imaging of P3HT:PCBM photovoltaic blend: evidence for interfacial charge transfer state," Journal of Physical Chemistry Letters, vol. 2, no. 9, pp. 1099-1105, 2011.

[4] I.-W. Hwang, D. Moses, and A. J. Heeger, "Photoinduced carrier generation in $\mathrm{P} 3 \mathrm{HT} / \mathrm{PCBM}$ bulk heterojunction materials," Journal of Physical Chemistry C, vol. 112, no. 11, pp. 4350-4354, 2008.

[5] S. Trotzky, T. Hoyer, W. Tuszynski, C. Lienau, and J. Parisi, "Femtosecond up-conversion technique for probing the charge transfer in a P3HT : PPCBM blend via photoluminescence quenching," Journal of Physics D, vol. 42, no. 5, Article ID 055105, 2009.

[6] J. Guo, H. Ohkita, H. Benten, and S. Ito, "Near-IR femtosecond transient absorption spectroscopy of ultrafast polaron and triplet exciton formation in polythiophene films with different regioregularities," Journal of the American Chemical Society, vol. 131, no. 46, pp. 16869-16880, 2009.

[7] J. Guo, H. Ohkita, H. Benten, and S. Ito, "Charge generation and recombination dynamics in poly(3-hexylthiophene)/ fullerene blend films with different regioregularities and morphologies," Journal of the American Chemical Society, vol. 132, no. 17, pp. 6154-6164, 2010.

[8] R. Alex Marsh, J. M. Hodgkiss, S. Albert-Seifried, and R. H. Friend, "Effect of annealing on P3HT:PCBM charge transfer and nanoscale morphology probed by ultrafast spectroscopy," Nano Letters, vol. 10, no. 3, pp. 923-930, 2010.

[9] J. Piris, T. E. Dykstra, A. A. Bakulin et al., "Photogeneration and ultrafast dynamics of excitons and charges in $\mathrm{P} 3 \mathrm{HT} /$ PCBM blends," Journal of Physical Chemistry C, vol. 113, no. 32, pp. 14500-14506, 2009.

[10] I. A. Howard, R. Mauer, M. Meister, and F. Laquai, "Effect of morphology on ultrafast free carrier generation in polythiophene: fullerene organic solar cells," Journal of the American Chemical Society, vol. 132, no. 42, pp. 14866-14876, 2010.

[11] S. Cook, R. Katoh, and A. Furube, "Ultrafast studies of charge generation in PCBM: P3HT blend films following excitation of the fullerene PCBM," Journal of Physical Chemistry C, vol. 113, no. 6, pp. 2547-2552, 2009.

[12] S. Cook, A. Furube, and R. Katoh, "Analysis of the excited states of regioregular polythiophene P3HT, Energy and Environmental Science, vol. 1, no. 2, pp. 294-299, 2008.

[13] W. Ma, C. Yang, X. Gong, K. Lee, and A. J. Heeger, "Thermally stable, efficient polymer solar cells with nanoscale control of the interpenetrating network morphology," Advanced Functional Materials, vol. 15, no. 10, pp. 1617-1622, 2005.

[14] Y. Kim, S. Cook, S. M. Tuladhar et al., "A strong regioregularity effect in self-organizing conjugated polymer films and highefficiency polythiophene:fullerene solar cells," Nature Materials, vol. 5, no. 3, pp. 197-203, 2006.

[15] O. J. Korovyanko, R. Osterbacka, X. M. Jiang, and Z. V. Vardeny, "Theory of the electronic structure of the alloys of the actinides," Physical Review B, vol. 64, no. 23, Article ID 235122, 10 pages, 2001.

[16] X. M. Jiang, R. Osterbacka, O. Korovyanko et al., "Spectroscopic studies of photoexcitations in regioregular and regiorandom polythiophene films," Advanced Functional Materials, vol. 12, no. 9, pp. 587-597, 2002.

[17] T. Yasuda, K. Yonezawa, M. Ito, H. Kamioka, L. Han, and Y. Moritomo, "Photovoltaic properties and charge dynamics in nanophase-separated F8T2/PCBM blend films," Journal of Photopolymer Science and Technology. In press.

[18] J.-H. Huang, C.-P. Lee, Z.-Y. Ho, D. Kekuda, C.-W. Chu, and K.-C. Ho, "Enhanced spectral response in polymer bulk heterojunction solar cells by using active materials with complementary spectra," Solar Energy Materials and Solar Cells, vol. 94 , no. 1, pp. 22-28, 2010.

[19] K. Yonezawa, H. Kamioka, T. Yasuda, L. Han, and Y. Moritomo, "Charge-transfer state and charge dynamics in poly $(9$, 9-dioctylfluorene-co-bithiophene) and $[6,6]$-phenyl $\mathrm{C}_{70}$-butyric acid methyl ester blend film," Applied Physics Express, vol. 4, no. 12, Article ID 122601, 2011.

[20] H. Kamioka, Y. Moritomo, W. Kosaka, and S. Ohkoshi, "Charge-transfer dynamics in cyano-bridged $M_{\mathrm{A}}-\mathrm{Fe}$ system $\left(M_{\mathrm{A}}=\mathrm{Mn}, \mathrm{Fe}\right.$, and Co)," Journal of the Physical Society of Japan, vol. 77, no. 9, Article ID 093710, 2008.

[21] R. Lim, B.-J. Jung, M. Chikamatsu et al., "Doping effect of solution-processed thin-film transistors based on polyfluorene," Journal of Materials Chemistry, vol. 17, no. 14, pp. 14161420, 2007.

[22] P. Ravirajan, S. A. Haque, D. Poplavskyy, J. R. Durrant, D. D. C. Bradley, and J. Nelson, "Nanoporous $\mathrm{TiO}_{2}$ solar cells sensitised with a fluorene-thiophene copolymer," Thin Solid Films, vol. 451-452, pp. 624-629, 2004.

[23] C. H. Poh, L. Rosa, S. Juodkazis, and P. Dastoor, "FDTD modeling to enhance the performance of an organic solar cell embedded with gold nanoparticle," Optical Materials Express, vol. 1, pp. 1326-1331, 2011. 

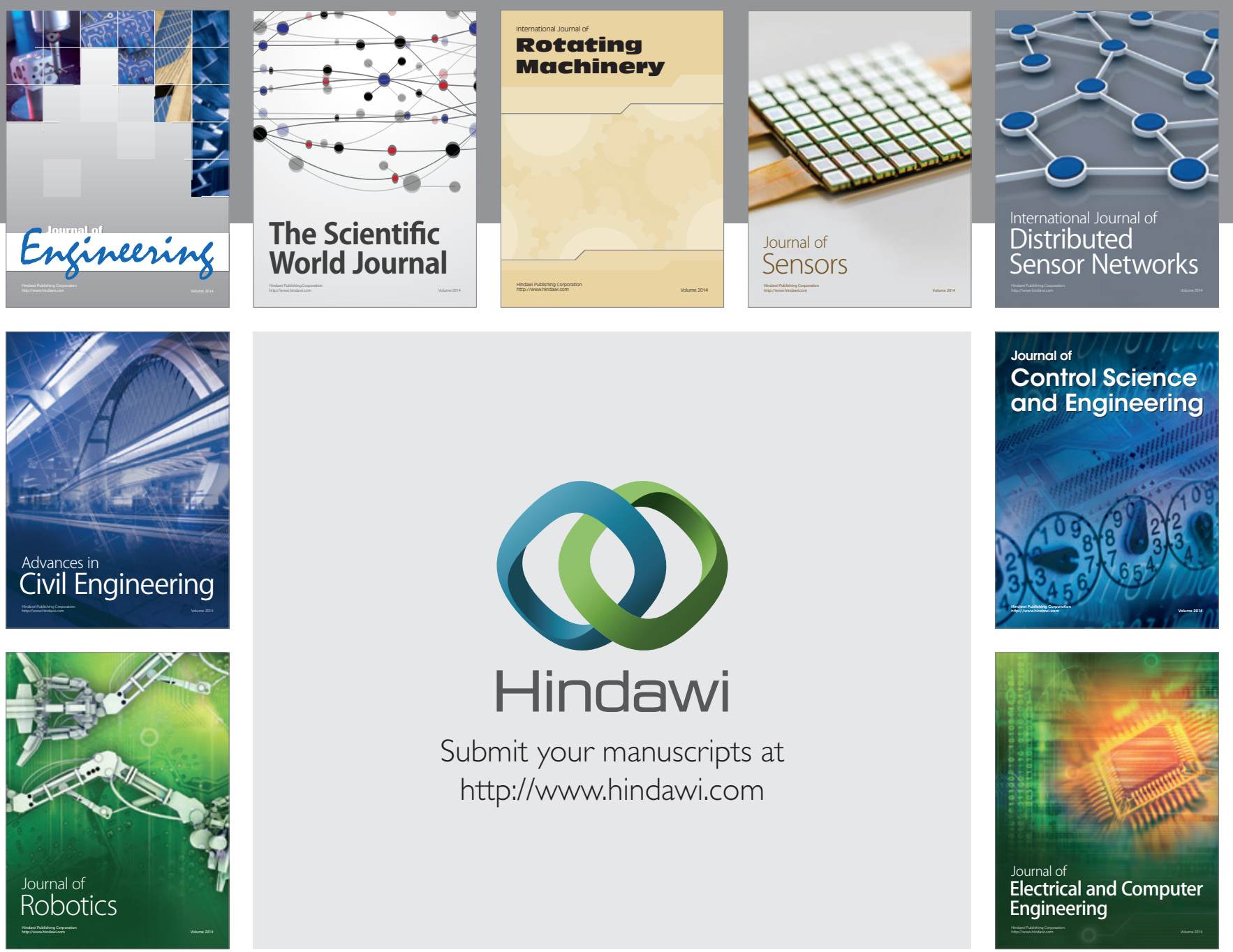

Submit your manuscripts at

http://www.hindawi.com
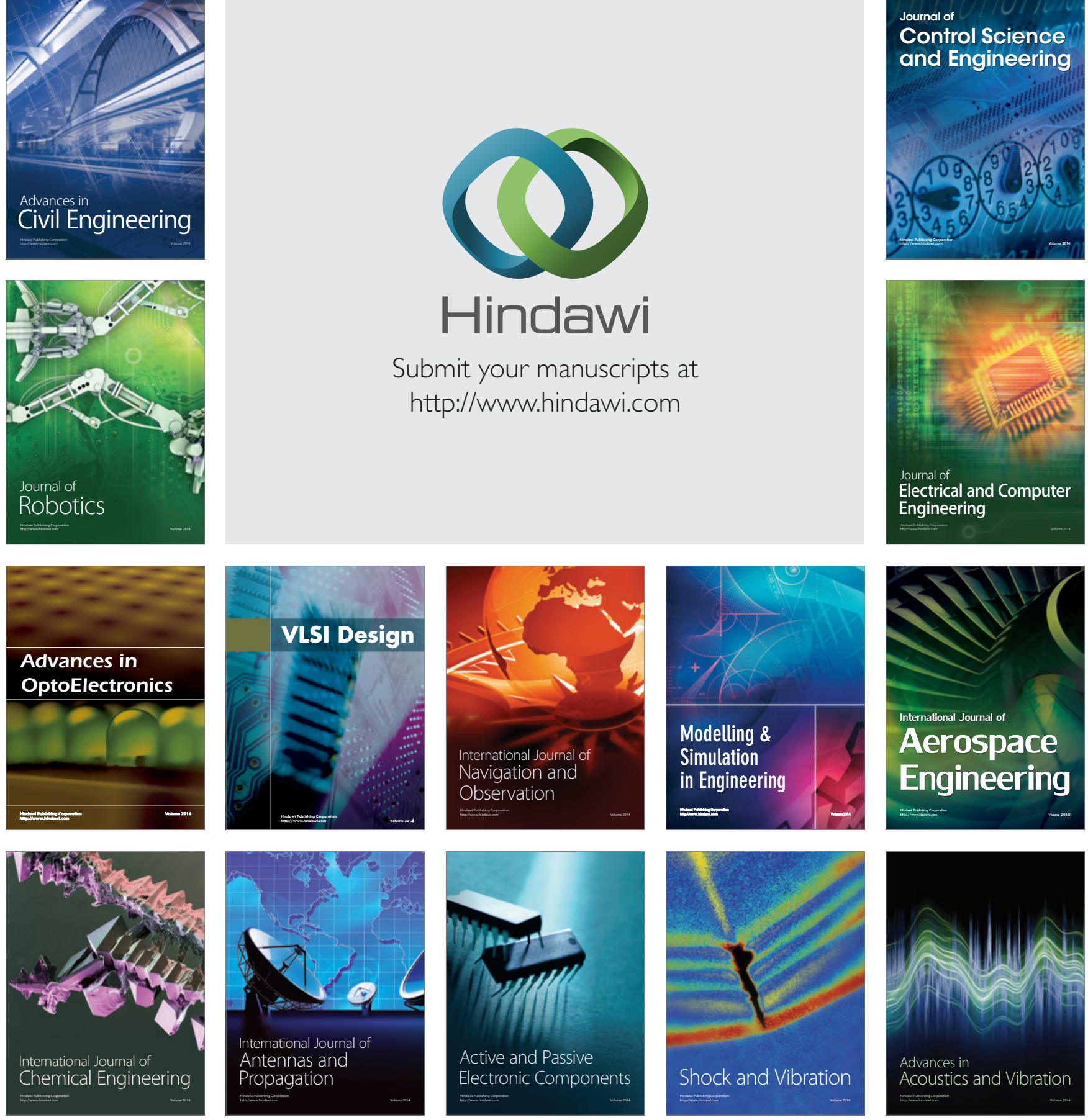